\title{
Art and cultural institutions as social extensions of personal self-identity
}

\author{
Jacek Olender \\ The Institute of Philosophy and Sociology, \\ The Polish Academy of Sciences, Warsaw. \\ The Courtauld Institute of Art in London \\ jolender@sns.edu.pl
}

\begin{abstract}
The paper discusses artworks and artefacts considered as both cultural heritage and meaningful tokens for personal self-identity. The arguments come mostly from phenomenological understanding of self-identity and art, but the terminological toolkit comes mostly from the Extended Mind Thesis. While many museologists and theorists of culture argue that objects presented in a particular social context can shape group identity, I believe in taking this question to a lower, personal level. In this paper, I argue that we build our self-identity partially by anchoring our memories with significant art and heritage objects. I state that artworks, mediated by cultural context immersion of museums and galleries, serve as self-identity extensions. Since I find both selfidentity and art structured as sets of cultural meanings wrapped in material scaffoldings, I draw a relation between those two, showing the crucial meaning of material cultural objects for the formation of our self-identity.
\end{abstract}

Keywords: self-identity; extended mind thesis; art; artworks; cultural heritage; material heritage; phenomenology; aesthetics; museology; politics of display.

\section{Introduction}

In the field of museum studies and heritage preservation and management, theorists widely accept the view that being directly involved with cultural artefacts from the past shapes both individual and group identities. The 'politics of display', as this problem is sometimes referred to, is an attempt to track down these influences in order to make museums as inclusive as possible, while also keeping them as informative as possible. Numerous authors point out that interactions with objects exhibited in a specific context in museums 
are able to shape group and individual identities (Conn 2010; HooperGreenhill 1992 \& 2000; Luke 2002; Macdonald 1998). However, analyses carried out in the field of museology focus on the social dimension of this phenomenon and deal with these problems mainly on a political level with a critical theory toolkit. My interests lie at the level of the particular individual. How can such identity shaping happen on a personal level and later accumulate to form a group identity?

In this paper, I will show how art and cultural heritage artefacts can be considered vehicles for the ability of our minds to identify ourselves as unique persons. There are several theories that search for the inclusion of external factors in the environment into the functions of the mind. I use terminological tools developed within the realm of the broadly understood extended mind thesis and from phenomenology, especially phenomenological aesthetics. My argument goes as follows. The extended mind thesis (EM) shows how we use external objects to increase the cognitive capacity of our minds. I state that we can consider self-identity as a cognitive function of our mind, part of a system that helps us to create a framework for other processes. Using phenomenological concepts of art and aesthetics, I reconstruct the phenomenological understanding of art in which cultural meaning is directly connected with personal meaning and add arguments from contemporary actionperception-based aesthetics. Finally, I formulate a claim of a distinct relation between the construction of a work of art and the structure of the selfidentity, relying on their multi-layered structures where physicality interweaves with cultural aspects. This relation shows that material artefact-based cultural activities, including art creation and reception, are important factors in shaping our self-identity. This idea is in the end supported by the concept of meaning in accordance with material objects that are related to selfidentity. In the end, this all leads to the accumulated identities of people as members of groups in reflexive relation between personal and cultural identities.

I start the paper with a short description of the principles of the extended mind (EM) thesis proposed by Clark and Chalmers (1995/2011), later repeated by Clark alone (2008). I use only the most important parts of the original EM thesis, supplementing them with a less 'canonical' understanding of this thesis. Then, in section 2, I describe my understanding of the works of art with their dualistic material and symbolic structure. I introduce the phenomenologists' ideas of intentional object and intentionality. All this is supported with contemporary action-perception-based aesthetics. Next, in section 3, I briefly introduce the basic problems concerning the idea of self-identity. I argue that self-identity is an existent function of the mind and using this concept effectively helps in explaining many problems in theory of mind. Finally, in section 4, I show that our minds can use objects of cultural heritage to offload some of their self-identification functions onto the surrounding material reali- 
ty and therefore create 'self-identity extensions'. I claim that cultural artefacts that we read on a daily basis are used by our minds to shape our personal identity as unique individuals and as members of specified cultural circles.

\section{Extended Mind}

In their original paper, Clark and Chalmers (1998/2011) argue that cognitive processes take place not only inside the head of the subject, but can be extended to certain objects in the environment. The central argument is the parity principle, which states that the objects in our environment help us perform cognitive tasks we normally would perform in our heads; hence, these objects can be considered parts of the extended cognitive systems (Clark \& Chalmers 1998/2011). These systems are coupled with the neural cognitive system in a way referred to by Menary (2010a) as active causal coupling ${ }^{34}$. This means that extended systems can actively influence our internal systems and through them, or jointly with them, shape our behavior. Clark (2008) puts restrictions on the thesis, limiting it to resources that are (1) reliably available and typically invoked, (2) deemed about as trustworthy as something retrieved clearly from biological memory, (3) that contain information in a way that is easily accessible as and when required, and (4) that the information they contain has been consciously endorsed at some point in the past and indeed is there as a consequence of this endorsement (2010a: 79).

Margaret Wilson in her paper Six Views on Embodied Cognition (Wilson 2002) has put forward six claims regarding embodied cognition. Claims 3 and 4 are most important for my investigations here.

Claim 3 is we off-load cognitive work onto the environment (2002: 628). Wilson presents examples that show how our mind is keen on transforming direct surroundings to help it perform cognitive tasks. By manipulating objects, we help ourselves execute not only very complicated tasks, but also simple ones. We do it, for example, by simple spatial organization or, as is more important here, by something Wilson calls symbolic off-loading (2002: 629). This happens when we group objects or tasks and we label these groups with symbols (sometimes even just in the mind). Later, we are able to manipulate just the groups.

Claim 4 is [t]he environment is part of the cognitive system (2002: 629). This is a claim that includes the extended mind thesis as our minds can pull the environment into its cognitive structure to solve particular cognitive problems and enhance our cognitive capacities.

\footnotetext{
${ }^{34}$ The causality of coupling the mind with external objects is however discussed (for example, Adams \& Aizawa 2010; Gallagher 2013).
} 
The other claims consider our cognition as (1) situated, (2) time-pressured, (5) prepared for action, and (6) off-line (without the environment present) body-based.

I believe that Clark and Chalmers, as well as Margaret Wilson, are right to claim that humans tend to transfer some cognitive processes to-or suspend them on-the material world around us. Even if we were to accept reservations put forward by critics of the EM thesis (as in Adams \& Aizawa 2008) that we should not claim that cognitive processes happen outside the brain and therefore extend the mind into the environment, we still may accept lighter claims that minds sometimes depend on the environment in performing cognitive tasks.

What is important for my argument is the fact that the EM thesis is partially memory-focused. The famous Inga and Otto example taken from Clark \& Chalmers (1998), and Clarke (2008) shows how multi-step the process of mind extension is. Both Otto and Inga want to go to the art museum in New York. Inga remembers the location of the institution, while Otto has it written down in his notebook that he consults each time he wants to get there, as he cannot recall the location on his own. The first step in Otto's mind process happens when the information is consciously put into the notebook. Second, there is the unconscious memorizing of the information being stored in the notebook. Here is the moment of confrontation of the mind with a certain situation combining Otto's states of mind (the will to go to the museum and deficient information in his memory) with the world (the museum is somewhere in the world). Otto wants to go to the museum, but he does not remember where it is. Here is the third level: Otto's unconscious belief that the information is stored in the notebook. In the last, fourth step, Otto retrieves and uses the information. We can see that information stored in the outside world was originally a part of the original bearer's memory and was later transferred, probably along with other memorized information, to external storage.

More liberal takes on EM thesis include social institutions that allow us to depend on them when we shape our behavior. Such accounts have been presented by Gallagher \& Crisafi (2009), Gallagher (2013) or Krueger (2013). I believe that cultural and social institutions deserve to be treated within this account as parts of the environment that allow us to offload some mind functions onto them. I propose that Gallagher and Crisafi (2009) started going in the direction; however, they have instead focused on the institution of the museum as a social construct, mentioning more the organizational and spatial dispositions of the institution itself, rather than focusing on the interaction with particular artefacts. They rightly point out that, for example, the chronological order of a museum exhibition directs viewers' ways of thinking on an external track proposed by the museum's curator. From this point forward, 
a viewer referring to a particular period in art history seen at this exhibition will think of it in the way she saw it at the exhibition. If she forgets the chronology, she would always be able to refer back to the exhibition or the exhibition catalogue she might have bought there. The exhibition becomes an extension of knowledge. As far as I agree with this statement, I believe it still does not go far enough. I will elaborate on this in section 4 .

\section{Self-identity}

The ideas of self-identity and selfhood are needed for their explanatory power when analyzing personal action, subjective cognition or consciousness. They are also necessary when speaking of the social behavior of humans (Zahavi 2008; Campbell 2011).

Self can be described in many dimensions; however, in this context we should consider personality or personal identity. Human personality consists of a string of experiences in time, connected by immanent causation (Campbell 2011). This means that some properties or conditions of the self from the past are causally connected to properties and conditions in the future. Selfidentity needs to recognize the time sequence of events and causality, referring the subject to both of them. Because it perceives the string of events and experiences the time-immersed sequence of perceptions, self can be considered as a narrative. Such a concept, developed by Paul Ricoeur, considers self as a 'story' (for lack of a better term), a tale about specific events in time in relation to the subject. However, this time is neither the objective time of the universe, nor is it absolutely subjective: it is a 'personal' time that is somewhere between the two (Zahavi 2008).

On one hand, self-identity is conditioned by the subject's relation with the body, with dead external objects in the world, and through relations with other subjects. On the other hand, self-identity is shaped by social reality, with all its practices, rules and complications (Gergen 2011).

The time-immersed self needs a 'place' to unite the string of events and relate them to each other in order to make the recognition of the causal structure possible and to create a narrative self. This place is memory, where all these processes combine. This is also the place where from one can recall social norms and rules of practices. Self-identity can be 'constructed' in the memory of the subject. Here I follow writings of phenomenologists, as described by Zahavi (2008: 105-106), who showed the need for memory in the construction of self-identity. We can be aware of our self-identity only if we remember who we are. 
Therefore, the self has a bi-layered structure consisting of embodied sensual experiences and socio-practical narrative. Memory-based self-identity needs material vehicles that facilitate access to currently needed points of reference in its structure. I believe that self-identity is a derivative of cognitive functions of the mind, the same way other cognitive manipulations or perceptions of external world are. Self-identity is based on bodily experience of the nervous system and the senses. It is also based on the relation between subject and environment and is dependent on the cognitive capacity of the mind (Parnas \& Sass 2011). I think that these general statements about self-identity can be defended on the grounds of both extended cognition-for which mostly functionality matters, as in Menary (2010a) - and also on the grounds of cognitivism (Adams \& Aizawa 2010), as discussed by Menary (2010c).

For my argument, I focus mainly on the aspects of constructing the notion of self-identity that would be based on culture. We are used to defining ourselves not only by relating to our bodies, but also to different aspects of our social existence. The first of these aspects are the aforementioned simple interpersonal relations. Second are the broadly defined social groups of which we are members. By these, I mean all the groups from family, through our school and university peers, work colleagues, political parties, up to nationality or citizenship. I limit my argument to the second aspect of the social base for creating the notion of self-identity. We can see that in our relation to the university we have studied at, to the work we perform (like 'I am a philosopher/IT-guy/lawyer' etc.) there is an element of identification of a person with a group. The social institutions we are part of usually require some level of personal identification. This can be easily seen with examples of educational institutions or workplaces. People are often identified within our culture on the basis of the institutions or companies they work for, the places they like to visit, and the schools they have graduated from. The social, external identification influences the self-identification with those institutions as significant for a particular individual.

\section{Art}

Classical research of art historians has concentrated on following cultural trends in the history of art or reinterpreting artworks in the light of a particular theory (e.g. Marxist theory or literary theory). This section is focused on art considered in the first place as material objects, immersed however in social and cultural context. Here I consider material objects that are commonly acknowledged as art, i.e. socially grounded as objects of art, or are at least publicly discussed as objects of art (e.g. Banksy's graffiti). I will discuss art as material objects that have special, symbolic meaning and are involved in a very particular set of social practices. 
Roman Ingarden, a Polish phenomenologist and student of Husserl, has pointed out in his work on aesthetics that a work of art is a peculiar object that differs from other material objects (Thomasson 2012; Szczepańska 1989a). I follow Ingarden's argument that a material artefact that is considered art consists of at least of two ontological layers. The first is culturally grounded: symbolic, aesthetic, and historical. The second is the 'simple' materiality. The physical object is a 'skeleton' (or scaffolding) for the aesthetic layer. According to Ingarden, a work of art is an intentional object, which means its existence is equally conditioned by the intentions of the creator and by the intentions and comprehensive capabilities of the subject 'reading' it. However, the intentions of all parties must be-as must everything that takes place in our physical world - mediated by the 'material' skeleton on which the work of art is built (Szczepańska 1989a; 1989b). The quotation marks around the world 'material' are no accident. For Ingarden, the skeleton for an artwork can be anything that is possible to be perceived more or less objectively. According to Ingarden, this role can be performed, of course, not only by material objects (like brushstrokes on canvas), but also by the sound that carries a musical composition to an audience's ears. The objectivity of this perception can (and should) be disputed, as there are clear counterexamples in the form of people with vision or hearing impairments, or even vision history (as in Nanay, 2016). However, despite the differences in normal vision between people, Ingarden treats basic perception as objective. I believe that with restrictions in mind, we can follow Ingarden's thought. According to Ingarden, the actual reception of the artistic object takes place in the head of the perceiver when he simultaneously grasps the materiality and purely aesthetic value of the object, and the symbolic or narrative content. This process is referred to by Ingarden as concretization (Szczepańska 1989a; Thomasson 2012), which is the process of 'compiling' the aforementioned aspects of art's existence into one experience. A single artwork can be concretized in various ways, even by one subject, when focusing on different aspects at different readings (Szczepańska 1989b).

According to Ingarden's theory, materiality is no less important than the socio-cultural context. He points out that grasping the aesthetic values and intentionality of an artefact by the subject is determined by his/her experience and socio-cultural competence. Additionally, as Rudolf Arnheim (1969) states, in the case of art, physiological level of perception and intelligible understanding are mutually interwoven. In terms of visual communication, perception itself is part of analytical thinking and the two cannot be separated. This research trend is currently pursued by neuroaesthetics, which is a field investigating the involvement and influence of the senses on aesthetic experience (Francuz, 2008). 
Ingarden's work brings forth the complexity of the process of art creation. In this process, the intentionality is crucial for my argument. This term should not be confused with only intentions (although they are also important here), but it is more of a mode of being.

The intentional creation of a work might be understood in today's language as a form of 'coding'. This means that the artist creates the work with the intention of later extraction of aesthetic and symbolic experience from it by viewers who retrieve the 'information' (aesthetic experience and symbolic content). According to Ingarden, in order to acquire the information from the artwork, the viewer is forced to perform an ongoing, continuous process of compiling all the information aspects he can retrieve from the work scrutinized. This is what Ingarden means when talking of concretization. The intentions of the artist during the creation of the artwork are 'encoded' within the object and later intentionally grasped along with the sensual perception by the viewer. Because of this, the full existence of the artwork is possible only when it is being read; its existence becomes intentional. Otherwise, it is just a bit of paint or other material. The intentions are required to create the artwork, but should not be mistaken for the intentionality, the latter being a mode of the artwork's existence (Szczepańska 1989a; 1989b; Brunius 1970).

The concretization process includes not only sensory data retrieval, but also all the mental and culturally grounded associations (such as the interpretation of the symbols depicted in the artwork). However, I suggest that we must divide the process of purely sensory data retrieval and pure mental associations (such as the experience of color) from the symbolic interpretations of the higher level. The best example of such a need is abstract art. We do not 'think' about the symbolic content of an abstract painting when first glancing at it. It is only in the (at least) second step that we make associations with the cultural context of the painting and interpret it on a socio-cultural level. Therefore, it is possible for us admire the artist's concept and the significance of the artwork in art history while feeling no aesthetic pleasure from looking at it. The first issue is related to intelligible understanding of art, while the second might be just a simple combination of sensory data or our cultural upbringing in a different aesthetic circle.

In his book Aesthetics as philosophy of perception (2016), Bence Nanay suggests a similar approach to perceiving artworks. He develops the concept of three-fold attention in which the beholder simultaneously grasps three aspects of a picture: its physical surface, the depiction of an object, and the object itself. In later parts of this book, he suggests that, especially in case of performance art, people tend to identify themselves with the protagonists pictured in art, mainly in films and theatre. He does not however mention possible identification with an artwork on a level of personal importance. 
We tend to pay attention to different aspects of an artwork, while simultaneously placing the artwork in the socio-cultural sphere where it becomes meaningful as a general cultural artefact. Placing the artefact in a cultural context creates a reciprocal relation in which the object creates the cultural environment while simultaneously being defined by the same environment. Hence, social institutions, by creating the environment for the artefacts, also direct the ways in which the artefacts are read.

\section{Art as EM of self-identity}

Here I come to the key argument of my paper. In my opinion, objects of art can and should be considered as material vehicles for self-identity in the same way as different artefacts are described in extended mind theory. As I have mentioned in previous paragraphs (section 1), I think that we should focus on the materiality of a work of art and think of its significance for our selfidentity. I think that the material persistence of the object of art leads to a situation in which they are treated by the mind as extensions of self-identity that remind us of our cultural immersion and education and places us within a social group.

The extended mind thesis revolves around cognitive capacities of the mind that are scaffolded or enhanced by the external objects or social institutions with which our minds interact (Clark 2008; Sterelny 2010; Gallagher 2013). Some researchers suggest the crucial influence of material objects on the development of the human mind in the process of evolution. Jeffares's research (2010) shows how our minds have co-evolved with our tools, causing expansion of our cognitive capacities, more complex tools, and so on, in ongoing reflexive relation. Along with ecological transformations, such feedback loops led to an enormous explosion in intelligence in the hominid lineage (Sterelny 2007). Malafouris (2013) follows this lead, suggesting development of mind in the process of thinking through action in the material world and through the creation of tools. This reflexive relation loops tools and minds in a constant process of improvement. However, this body of research does not cover the problems of self-awareness and recognition of the self. Can this area of human cognition be influenced by the biological and social environment? I think we have external tools for self-identification. I see in this place symbolic objects of our culture that are present in different forms all over the world.

In section 1, I mentioned two claims of embodied cognition described by Wilson (2002). I think that the notion of self-identity, in which artistic objects of culture play the role of points of reference, fits these claims. In relation to claim (3), artistic objects can serve as a structure for the symbolic off-loading of self-identity functions; therefore, they form an environmental part of (claim 4) the cognitive system. 
The third rule considers the availability of the information. We should then think about what the information actually is in the context of self-identity. I say that the encoded information here is the ability to say 'this is me, but also this is my [folk, nation, country, group, etc.]'. I think that when a subject is confronted with a work of art of particular meaning, it becomes a point of reference for the subject, mediated by the cultural theme it contains and therefore serving as information off-loading labels for complicated matters of identity.

However, one can argue that the information about the relation of the subject to his self-identity under the influence of a work of art is not recalled intentionally. I would answer that the whole notion of self-identity is ontologically not intentional; therefore, this argument has no power here.

However, we must notice that this is different kind of information and a different kind of intentionality than that described in section 1 . According to Ingarden (Szczepańska 1989a), meaning is put intentionally in a work of art by the author and is retrieved intentionally by the perceiver. However, what I refer to here is the information derived by the subject from the very fact of confrontation with a material object that also happens to have particular cultural meaning. Therefore, the anchoring of the self happens through contact with the socially grounded, but yet material object. Here, another argument can be made that contrasts with my statements: the parity principle says nothing about the cultural reference of the objects. Partially following Gallagher \& Crisafi (2009), Gallagher alone (2013) and Krueger (2013), I would answer that all the practices of extension offered by Clark are culturally and socially immersed. Hence, I say that the concept of art as an extension of selfidentity fulfils the parity principle from Clark (2008).

The point where symbolic artefacts serve as a scaffold for self-identity is the material reference point for our memory. Due to their temporal persistence in more or less one physical form, they are available to serve us as reminders of our previous experiences. Previously, in section 2, I showed that self is a time-immersed chain of experiences and sensations. Our memory is the place to which consciousness can appeal for reassurance. Having material, persistent points of reference with significant cultural meaning can simplify the recalling of the conscious notion of self-identity. This happens in the same way as in Clark's description of inclusion of cognitive extension that happens in order to facilitate cognitive actions of the mind. Having a material point of reference for our culturally immersed personality simplifies the selfrecognition of the subject by off-loading some of the burden from memory to the external world. 
A perfect example here could be made with western school systems, for which 'patriotic' education has a significant position. Children are shown many artefacts that are described as 'national'. Teachers show the most important objects of a particular culture to children and explain why this is 'their' culture and how this object 'represents' it. An analogous example comes from history: Nazis in pre-war Germany held exhibitions of so-called Degenerate Art (Entartete Kunst), which were supposed to show society that avant-garde art (which was modern at that time) contradicted the ideals of the German nation (Barron, 1991). We see that art was supposed to shape the 'right' idea of nation and lead to proper self-identity of members of that nation. The discussions held at museums worldwide on presenting nations and races epitomize the very same problem. How should public discourse concerning selfidentification be directed? In this situation we point to external discourse as if it happened in someone's head and led to his or her self-identification.

How can this process be described? I suggest we should come back to the phenomenological idea of intentionality. In Ingarden's work, we see the process happening in a particular manner. In the first instance, content is 'coded' (for lack of a better word) by the creator: his will to pass on his ideas leads to particular artistic results. Of course, these results are dependent on his artistic skills, the available materials, and his cultural background that leads to the use of a certain 'code'. In the process of concretization, which is a specific kind of perception, 'decoding' goes the other way round. The perceiver needs not only sensory abilities to grasp the material features of the work, but also needs the proper cultural background to 'decode' the work of art. If his senses are significantly different from the creator's, his 'decoding' might lead him to results unpredicted by the creator. The same goes for the cultural background. Finally yet importantly, we must remember about the ecology of both processes that might derail the final results. Therefore, the work of art is intentional: it is only fully present in the intentional grasp of all the participants in the process. Intentionality is realized when the object is grasped with all its aspects and the viewer makes personal sense of it. Our self-identity, which is based on perceptual experiences but immersed in cultural entanglements, relates to artworks that have the same basic phenomenological structure: a physical appearance bearing a multitude of cultural meanings and dependencies. In addition, the very fact of the materiality of an artefact-its temporal persistence-bears its own meaning, i.e. it gives the individual a reference point in time.

I state that a similar process takes place when we shape our personal and social selves in enculturation into society. Only here is the very first intentionality of the creator of the work less important than the intentionality of the 'cultural mediators', be they parents, teachers, peers or, most importantly, ourselves. Their (or our) intentions become crucial in the process of the first reading of a work (or any other artefact) and the interpretations or ecology 
introduced by these mediators are internalized by the subject (us), thereby becoming part of self-identity. For example, a picture is shown to a subject at school by a teacher. The subject is instructed to see in this picture not only a picture, but also a portrait of an important military commander, along with a story of a war between the subject's country and another. In this war, the commander was an important figure who led his country to victory. I suggest that many times, when a subject happens to be confronted with a situation regarding his country and another, he might recall the portrait of the commander, helping him to identify himself as a citizen of his country. Therefore, the intentionality of grasping the full sense of a work of art becomes significant to the construction of personal self-identity.

The social institutions that enable us to interact with artefacts direct our personal identifications with the objects. The ways in which objects are contextualized become the ways in which we identify with them. At a group level, cultural institutions shape identities discursively, while on a personal level the identification happens as a memory-based extension in which the object becomes a hallmark of an individual's relation to the cultural circle.

My argument can and should be seriously expanded to other cases of personal identification via material objects. For example, tokens of personal memories-be they jewelry inherited from a grandmother, or a childhood toy-can serve as vehicles of one's personal identity bearing meaningful associations with memories of one's life. The same is true of objects of religious cults, national banners or state emblems. However, these types of objects require wider analyses that would embrace religious practices or civil patriotism rituals, in order to explain fully the cultural encryption of such symbols.

\section{Summary}

I believe this research can provide a slightly different perspective for aesthetics-especially empirically grounded aesthetics-when looking for the reasons that visual arts actually exist within almost every society in the world, and why they have been here since almost the beginning of humanity. This can also shine a little new light on the analysis of a work of art as a material object, and the cultural significance of this obvious fact.

I have defined new kinds of cognitive extensions that our minds can establish with the environment, i.e. objects of art. I have also shown that our selfidentity is a cognitive category that can be an object of extension into the world. I suggest that we need to think of art and other artefacts of material heritage in every culture as an extension of our personal self-identity. I argue that when we are confronted with a situation that requires us to recognize our personal self-identity, we intentionally (in Ingarden's terms) turn to the recall of material objects that are significant for self-identity. In the intentional pro- 
cess, we make sense of the material object and build our identity through it. This includes the cultural institutions that shape our identities on a very personal level and supply us with both artefacts and a crucial socio-cultural context for them. The 'politics of display' can be drawn from phenomena happening on an individual level.

\section{References}

Adams, F., Aizawa, K. 2010. The Bounds of Cognition. Chichester: Wiley-Blackwell.

Arnheim, R. 1969. Visual Thinking. Berkeley: University of California Press.

Barron, S., ed. 1991. 'Degenerate Art:' The Fate of the Avant-Garde in Nazi Germany. New York: Harry N. Abrams, Inc.

Brunius, T. 1970. The Aesthetics of Roman Ingarden. Philosophy and Phenomenological Research, 30(4): 590-595.

Campbell, J. 2011. Personal Identity. S. Gallagher, ed. The Oxford Handbook of the Self: 339-351.

Cassam, Q. 2011. The Embodied Self: 139-156. S. Gallagher, ed. The Oxford Handbook of the Self.

Clark, A. 2008. Supersizing the Mind. Embodiment, Action, and Cognitive Extension. Philosophy of Mind. Oxford: Oxford University Press. Source: http://doi.org/10.1080/095150 80903432798, 20.09.2015.

Clark, A., Chalmers, D. J. 2011. The Extended Mind: 27-42. R. Menary, ed. The Extended Mind. Oxford: Elsevier; originally published in Analysis, 58: 10-23. Reprinted in: P. Grim, ed. The Philosopher's Annual, vol. 21; reprinted in: D. Chalmers ed. 2002. Philosophy of Mind: Classical and Contemporary Readings. Oxford University Press.

Conn, S. 2010. Do Museums Still Need Objects?. Philadelphia: University of Pennsylvania Press.

Francuz, P. 2008. Wprowadzenie [eng. Introduction]. Przegląd psychologiczny, 51 (2): 105-109.

Gallagher, S. 2011. Introduction: A Diversity of Selves: 1-32. S. Gallagher, Ed. The Oxford Handbook of the Self.

Gallagher, S. 2013. The socially extended mind. Cognitive Systems Research, 25-26: 412. Source: http://doi.org/10.1016/j.cogsys.2013.03.008, 20.09.2015.

Gallagher, S., Crisafi, A. 2009. Mental institutions. Topoi, 28 (December 2008): 45-51. Source: http://doi.org/10.1007/s11245-008-9045-0, 20.09.2015.

Gergen, K. J. 2011. The Social Construction of Self: 633-653. S. Gallagher, ed. The Oxford Handbook of the Self.

Hooper-Greenhill, E. 1992. Museums and the shaping of knowledge. London: Routledge.

Hooper-Greenhill, E. 2000. Museums and the Interpretation of Visual Culture. London: Routledge. 
Jeffares, B. 2010. The co-evolution of tools and minds: Cognition and material culture in the hominin lineage. Phenomenology and the Cognitive Sciences, 9: 503-520. Source: http://doi.org/10.1007/s11097-010-9176-9, 20.09.2015.

Krueger, J. 2013. Ontogenesis of the socially extended mind. Cognitive Systems Research, 25-26: 40-46. Source: http://doi.org/10.1016/j.cogsys.2013.03.001, 20.09.2015.

Luke, T. W. 2002. Museum Politics. Minneapolis: University of Minnesota Press.

Macdonald, S. 1998. Exhibitions of power and powers of exhibition: an introduction to the politics of display. S. Macdonald, Ed. The Politics of Display. London: Routledge.

Malafouris, L. 2013. How Things shape the Mind. A Theory of Material Engagement. Cambridge. Massachusetts: The MIT Press.

Menary, R. 2007. Cognitive Integration. Mind and Cognition Unbounded. Houndmills: Palgrave Macmillan.

Menary, R. 2009. Intentionality and Consciousness. W. P. Banks, ed. Encyclopedia of Consciousness, Vol. 1: 417-429. Oxford: Elsevier.

Menary, R. 2010a. Introduction: The Extended Mind in Focus: 1-26. R. Menary, ed. The Extended Mind. Cambridge, Massachusetts: The MIT Press.

Menary, R. 2010b. Cognitive Integration and the Extended Mind: 227-244. R. Menary, ed. The Extended Mind. Cambridge, Massachusetts: The MIT Press.

Menary, R. 2010c. Introduction to the special issue on 4E cognition. Phenomenology and the Cognitive Sciences, 9 (November): 459-463. Source: http://doi.org/10.1007/s11097010-9187-6, 20.09.2015.

Menary, R. 2013. Cognitive Integration, Enculturated Cognition and the Socially Extended Mind. Cognitive Systems Research. Source: http://doi.org/10.1016/j.corsci.2008 .12.024, 20.09.2015.

Nanay, B. 2016. Aesthetics as philosophy of perception. Oxford: Oxford University Press.

Parnas, J., Sass, L. A. 2011. The structure of Self-Consciousness in Schizophrenia: 521546. S. Gallagher, Ed. The Oxford Handbook of the Self. Oxford University Press.

Sterelny, K. 2007. Social intelligence, human intelligence and niche construction. Philosophical Transactions of the Royal Society of London. Series B, Biological Sciences. 362(1480): 719-730. Source: http://doi.org/10.1098/rstb.2006.2006.

Sterelny, K. 2010. Minds: Extended or scaffolded? Phenomenology and the Cognitive Sciences, 9 (October): 465-481. Source: http://doi.org/10.1007/s11097-010-9174-y.

Szczepańska, A. 1989a. Estetyka Romana Ingardena [eng. Roman Ingarden’s Aesthetics]. Warszawa: Państwowe Wydawnictwo Naukowe.

Szczepańska, A. 1989b. The Structure of Artworks: 21-54. B. Dziemidok, P. McCormick, eds. On the Aesthetics of Roman Ingarden. Interpretations and Assesments. Springer.

Theiner, G. 2008. From extended minds to group minds - Rethinking the Boundaries of the Mental. Doctoral thesis submitted at Indiana University. Source: http://gradworks.umi.com/33/30/3330797.html, 20.09.2015. 
Theiner, G. 2011. Res cogitans extensa. A philosophical Defense of the Extended Mind Thesis. Frankfurt am Mein: Peter Lang.

Thomasson, A. 2012. Roman Ingarden. E. N. Zalta, ed. The Stanford Encyclopedia of Philosophy (Fall 2012 Edition). Source: http://plato.stanford.edu/archives/fall2012/en tries/ingarden/, 20.09.2015.

Wilson, M. 2002. Six views of embodied cognition. Psychonomic Bulletin \& Review, 9(4): 625-636. Source: http://doi.org/10.3758/BF03196322, 20.09.2015.

Zahavi, D. 2008. Subjectivity and Selfhood. Investigating the First-Person Perspective. Cambridge, Massachusetts: The MIT Press. 